\title{
EVALUACIÓN DE LA VULNERABILIDAD INTRÍNSECAA PARTIR DE MÉTODOS GEOFÍSICOS Y DETERMINACIÓN DEL POTENCIAL HÍDRICO EN EL ACUÍFERO ALUVIAL NARANJITO, QUEPOS, PUNTARENAS
}

\author{
Laura Castro (2010)
}

La zona de estudio se localiza en la cuenca baja del río Naranjo, en el sector de Quepos en la provincia de Puntarenas y cubre un área de $41,45 \mathrm{~km}^{2}$. Por tratarse de una región costera, los acuíferos de mayor producción quedan restringidos principalmente en las formaciones aluviales. El acuífero aluvial Naranjito representa actualmente una de las tres fuentes de abastecimiento de agua potable de la comunidad de Quepos y otras comunidades cercanas, por lo que se ha planteado como objetivo principal, caracterizar los parámetros hidrogeológicos e hidrogeoquímicos, para delimitarlo y cuantificar el potencial hídrico, así como evaluar mediante el método DRASTIC la vulnerabilidad.

La geología está compuesta por rocas ígneas y sedimentarias del Terciario Inferior y por depósitos aluviales Cuaternarios. El basamento regional lo constituye el Sub - Complejo Basáltico del Promontorio de Quepos, el cual es sobreyacido por la Fm. Caótica Punta Quepos, posteriormente se tienen los conglomerados y areniscas calcáreas de la Fm. Calcarenita Punta Serrucho y las lutitas y areniscas calcáreas de la Fm. Térraba, completando la secuencia estratigráfíca con los depósitos Cuaternarios, los cuales han sido subdivididos como antiguos y recientes, reconociéndose en este última unidad tres terrazas no cíclicas denominadas Londres, Paso Indios y La Managua. Estructuralmente, el área está dominada por fallas inversas como la Falla Longitudinal de Costa Rica, a la cual se asocian fallas normales con componente de desplazamiento de rumbo.

Con el fin de elaborar el modelo hidrogeológico conceptual del acuífero principal, se complementó el cartografiado geológico con exploración geofísica, utilizando los métodos de resistividad eléctrica tipo sondeo eléctrico vertical y el método electromagnético en el dominio frecuencial. Como resultado, se muestra que el acuífero se encuentra entre capas geoeléctricas con resistividades que van de 220 a 998 Í $\mathrm{m}$, con un espesor variable entre 1 y $36 \mathrm{~m}$. Se determinaron los sitios de influencia y efluencia del río Naranjo y quebradas mediante aforos diferenciales, se establecieron las líneas equipotenciales y la dirección de flujo, la cual predomina hacia el SW, se calculó un volumen de recarga potencial para toda el área de estudio de $77166500 \mathrm{~m} 3 /$ año que equivale al $51 \%$ del valor total de precipitación. Para la determinación de la recarga se consideran parámetros meteorológicos, capacidad de infiltración y propiedades físicas y uso actual de los suelos.

Con la caracterización hidrogeoquímica se demuestra la existencia de dos niveles de agua, uno en la Unidad de Depósitos Aluviales Antiguos, 
de composición bicarbonatada clorurada sódica magnésica y el otro en la Unidad de Depósitos Aluviales Recientes, de tipo bicarbonatada càlcica. Ambos niveles son de tipo libre, aunque en los depósitos recientes existen capas de arcillas y lutitas que lo semi confinan. El Acuífero Naranjito presenta un valor de transmisividad de $781 \mathrm{~m}^{2} / \mathrm{d}$, un coeficiente de almacenamiento de 0,1 y una conductividad hidráulica de hasta $22 \mathrm{~m} / \mathrm{d}$.

La vulnerabilidad intrínseca de la cuenca baja del río Naranjo, específicamente en el análisis del Acuífero Naranjito, es de alta a muy alta, a causa de la poca profundidad de los niveles del agua subterránea, la alta recarga, la composición del acuífero, el poco espesor de la zona no saturada, la baja pendiente y la alta conductividad hidráulica. Dadas las características de la cuenca y la vulnerabilidad, se espera que esta investigación sirva de herramienta en la toma de decisiones para controlar el crecimiento urbano, agrícola, industrial y turístico de la zona, monitorear las posibles fuentes de contaminación y asesorar en la conservación de los bosques, el manejo de los desechos sólidos y la contaminación del recurso hídrico. 